Proc. of the XI Int. Conf. - Ion Implantation and other Applications of Ions and Electrons, Kazimierz Dolny 2016

\title{
Plasma-Assisted Automated Precision Deposition of Powder Coating Multifunctional Systems
}

\begin{abstract}
D. Alontseva*, A. Krasavin, N. Prokhorenkova And T. Kolesnikova
East-Kazakhstan State Technical University, 69 Protozanov Str., Ust-Kamenogorsk, 070004, Kazakhstan

The paper describes the results of developing a new technology of precision application of powder coating multifunctional systems to protect surfaces of industrial products using the microplasma material processing complex with the assistance of an industrial robot. The choice of components for developing the multifunctional powder coating systems and the trajectory of the plasma source and processing modes is made on the basis of optimized condition identified by initial experimentation and mathematical modelling. The use of a robot with a programmable controller provides high accuracy and performance of coating deposition onto the parts with a complex shape. The application of this technology allows obtaining multifunction systems of powder coatings with a predicted nanostructure and a complex set of properties such as microhardness and corrosion resistance. These systems are designed to protect friction surfaces and cutting tools, as well as to protect and restore the surface of components operating in corrosive environments and at high temperatures.
\end{abstract}

DOI: 10.12693/APhysPolA.132.233

PACS/topics: microplasma, structure phase composition, powder coating, multifunctional systems

\section{Introduction}

Nowadays various types of thermal spray coating processes for surface protection against temperature extremes, corrosion and wear are actively developing all over the world [1]. Combustion flame spraying, high velocity oxy-fuel spraying (HVOF), plasma spraying, and microplasma spraying are widely used in a variety of industrial and medical applications [2]. Among the different existing plasma spraying processes, microplasma spraying (MPS) is comparatively new and offers specific and unique properties [3-6]. MPS is particularly characterized by low plasma power, low plasma gas flow rate, small spray spot (1-5 mm), and a possibility of forming a laminar jet with the length of 100-150 mm, which heats the refractory material in a stream of Ar plasma and provides low heat input into the substrate. These properties are very beneficial for the deposition of coatings on small parts or with high accuracy. However, there are still a number of challenges, and the most important among them is a problem of formation of coatings with the specified structure and properties.

The aim of this work was to use MPS to deposit coatings with reinforcing particles of intermetallic compounds with lamellar morphology by MPS. The layers with nanostructure in the form of lamellar intermetallics developed in the coatings should have improved heat resistance, just due to the presence of intermetallic compounds, which are known [7] to retain their structure and properties at elevated temperatures. These layers are also characterized by high hardness $[8,9]$. Our previous papers $[10,11]$ dealt with the selection of relevant

*corresponding author; e-mail: dalontseva@mail.ru components for developing multifunctional powder coating systems and appropriate trajectory of the plasma source and processing modes. This was based on mathematical modelling of the optimized condition determined by our initial experimentation $[12,13]$.

\section{Materials and method}

The research material is PG-19N-01 (Ni-based powder alloy with the additives of $\mathrm{Cr}(14-20 \%)$, B (3.5\%), Si $(4.3 \%)$, Fe $(7 \%)$, C $(0.8 \%)$ deposited onto the St3 steel (Fe - base, C - 0.25\%, Mn - 0.8\%, Si - 0.37\%, $\mathrm{P}-<0.045 \%)$ substrate by a plasma jet. In order to form the desired nanostructures in microplasma coatings there were used the same powders as for the plasma detonation coatings where these nanostructures were observed previously [8-11].

The microplasma deposition of powders onto the steel substrates was made out at a pilot production site established on the basis of East-Kazakhstan State Technical University equipped with industrial complex for microplasma processing of materials on the basis of Kawasaki RS010L industrial robot (Kawasaki Robotics, Japan). The robot arm has a mounted device for microplasma deposition of "MPN-004" powder coating (produced by Paton Institute, Ukraine), in which the powder is fed in a stream of argon onto a substrate of any shape. The mounting of the robot was performed by Innotech Ltd, Kazakhstan. To solve the problem of providing the desired trajectory of the plasma source, there was deweloped software which converts the drawings made in AutoCAD and Compass to the robot controller by selecting the graphics primitives (line, arc, etc.) from the drawings and transferring them into the commands for the robot arm movement.

A number of processes taking place in the coatings were simulated with the purpose to achieve the desired 
precipitation from the melt phase during the deposition and cooling processes, as well as during the additional treatment by a plasma jet. This includes the optimum choice of the power density of a plasma source on the coating surface and also an efficient speed of the source movement. A specific temperature field in the system of coating-substrate was created to provide the precipitation of hardening phases in the coating during the added treatment. During this procedure the coating surface is melted, whereas the area of the interface of the coating with substrate is exposed to the temperature of about $400{ }^{\circ} \mathrm{C}$ for several minutes. In our previous study the temperature distribution in the two-layer absorbers was calculated using both the permanent linear case model and the non-linear model with variable thermal parameters $[12,13]$. The deposition and additional treatment parameters are given in Table I. The additional treatment of the samples by a plasma jet was carried out at a power density of $2.0 \times 10^{9} \mathrm{~W} / \mathrm{m}^{2}$.

TABLE I

Regimes of coatings synthesis.

\begin{tabular}{|c|c|c|c|c|c|c|c|}
\hline$P[\mathrm{~W}]$ & $U[\mathrm{~V}]$ & $I[\mathrm{~A}]$ & 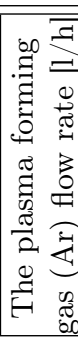 & 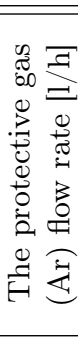 & 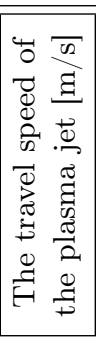 & 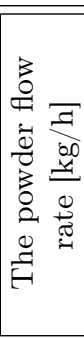 & 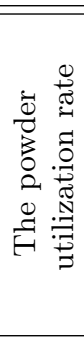 \\
\hline \multicolumn{8}{|c|}{ deposition } \\
\hline 2 & 30 & 40 & 70 & 360 & 0.008 & 2 & 0.7 \\
\hline \multicolumn{8}{|c|}{ additional treatment } \\
\hline 2 & 30 & 40 & 60 & 250 & 0.006 & - & - \\
\hline
\end{tabular}

The experimental methods of analysis include transmission electron microscopy (TEM) by JEM2100 (JEOL, Japan) with energy dispersive spectrometry (EDS) INCA Energy TEM 350 (Oxford Instruments, Great Britain), scanning electron microscopy (SEM) by JSM-6390LV (JEOL, Japan), X-ray diffraction (XRD) by X'Pert PRO (PANalytical, the Netherlands). M-691 Precision Ion Polishing System (Gatan, USA) was used to prepare TEM foils by the Ar ion sputter etching method. Microhardness test of the samples was performed with the LM-700 digital microhardness meter (LECO, Russia). Corrosion was tested using the potentiostatic method to measure the sea-water corrosion rate.

\section{Results and discussion}

The XRD methods allowed establishing that phase compositions of the initial powder PG-19N-01 and the microplasma coating are different (Table II). The new one $\mathrm{CrNi}_{3}$ intermetallic phase appears in the coating and the volume concentration of $\mathrm{Cr}_{13} \mathrm{Ni}_{5} \mathrm{Si}_{2}$ phase decreases by 2.5 times compared to the initial powder. As the TEM analysis demonstrates, the coating is mainly composed of crystallographically disoriented nanograins of Ni-based solid solution with the fcc type of crystal lattice (Fig. 1a), which precipitates nanoscale lamellae of the $\mathrm{CrNi}_{3}$ intermetallic phase with the same fcc structure (Fig. 1b). The EDX spectrum shows the presence of such elements as $\mathrm{Ni}$, $\mathrm{Cr}$, or $\mathrm{Fe}$, which is in a good agreement with the XRD results.

\section{TABLE II}

Phase composition of the investigated materials. In order: volume concentration [\%]|| chemical formula|| crystal system \| space group $\|$ space group number\| lattice parameters $[\AA]$

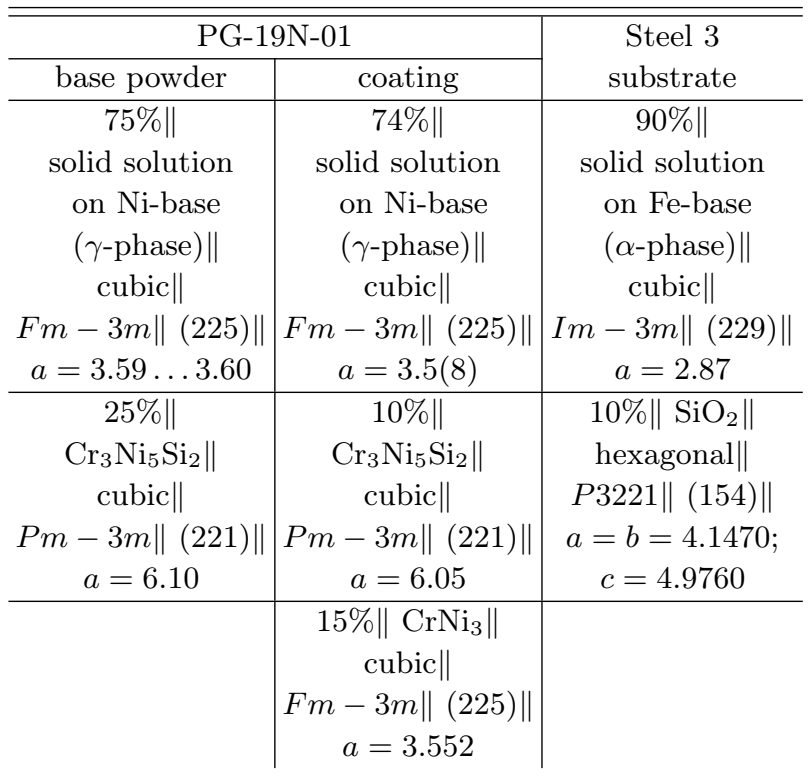

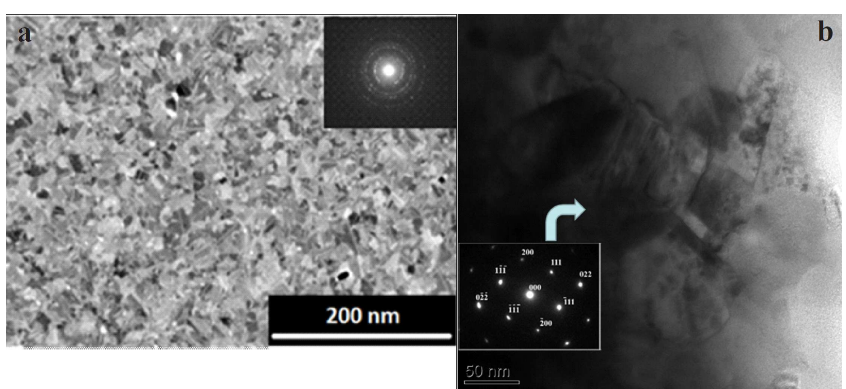

Fig. 1. TEM images of the PG-19N-01 coating with the corresponding microdiffraction patterns: the nanograin polycrystalline structure (a), the lamellas of intermetallic phases (b).

The SEM images of the coating surface show the broken powder particles (Fig. 2a). Using the TEM methods the twins in the substrate grains are observed (Fig. 2b). The twins appear probably due to lowering the stress in the surface layer of the substrate because of the impact of the plasma jet with powder particles.

The microhardness of the coating is $7.0 \pm 0.05 \mathrm{GPa}$ on average. The results of corrosion resistance test in 


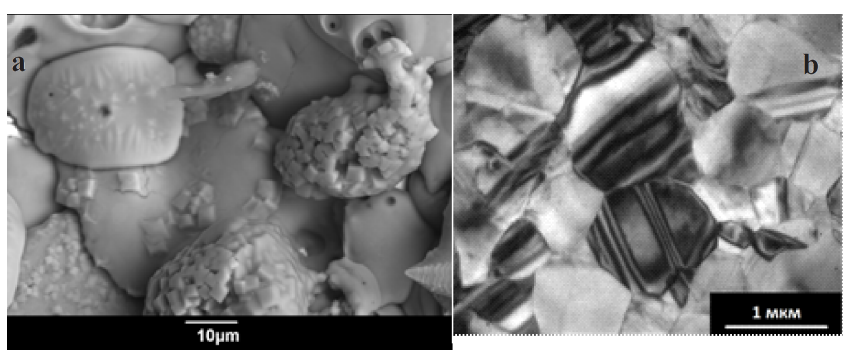

Fig. 2. SEM image of the PG-19N-01 coating (a), TEM image of the Steel 3 substrate (b).

the sea water confirm the sufficient growth of corrosion resistance for the coated samples compared to the unprotected substrate. Steel 3 substrate and PG-19N01coating sea water corrosion potential is rather high: $\varphi_{\text {corr }}=-0.28 \mathrm{~V}$ and $\varphi_{\text {corr }}=-0.35 \mathrm{~V}$ correspondingly. Yet the substrate corrosion rate is considerably higher: $i_{\text {corr }}($ substrate $)=3.9 \mathrm{~mm} / \mathrm{y}, i_{\text {corr }}($ coating $)=2.7 \mathrm{~mm} / \mathrm{y}$.

To sum up, we have managed to obtain the coatings with the predicted structure-phase composition and properties for specified materials. We suppose these results are quite important due to the following two reasons: firstly, the structure of coatings is similar to that of nanocomposite, the coating consists of the ductile base with the fcc lattice type which is reinforced by lamellas of hard and heat-resistant intermetallic phase. In perspective, it gives the possibility of creating a protective coating being a combination of such properties as thermal stability, high hardness and good ductility all at once, as noted also by the authors of $[2,4,6]$. Secondly, the results indirectly confirm the correctness of the computer stimulation of temperature profiles; therefore the correct model of the process as the whole and reliable software in particular were designed. In the future we can expand the database on thermal properties of various metals and the use of mathematical modelling in the practice of obtaining protective coatings.

\section{Conclusions}

A proprietary software product to perform calculations of temperature fields in a number of industrial materials under irradiation has been developed, and evidence-based recommendations on the choice of modes of surface modification by the microplasma (trajectory and speed of the plasma source, power density of the microplasma) have been provided. The laboratory samples with the protective powder coatings deposited by the microplasma according to the recommended modes onto the steel substrates were obtained. It was established experimentally that the coatings have the predicted structure-phase composition, namely the nanograin Nibased solid solution with precipitations of strengthening intermetallic lamellas which provide high microhardness of the coatings. The coatings have a good corrosion resistance in seawater. Thus, the scientific basis of surface modification technology by the microplasma exposure was developed and an automated pilot production site was implemented.

\section{Acknowledgments}

The authors thankfully acknowledge the funding provided by the Scientific Committee of the Ministry of Education and Science of the Republic of Kazakhstan for the project 0869 /GF titled "Automated precision deposition of powder coating multifunctional systems".

\section{References}

[1] S. Kuroda, J. Kawakita, M. Watanabe, H. Katanoda, Sci. Technol. Adv. Mater. 9, 033002 (2008).

[2] A. Vardelle, Ch. Moreau, J. Nickolas, A. Themelis, Plasma Proc. 35, 491 (2015).

[3] L. Wang, H. Wang, S. Hua, X. Cao, Plasma Sci. Technol. 9, 52 (2007).

[4] E. Lugscheider, K. Bobzin, L. Zhao, J. Zwick, Adv. Eng. Mater. 8, 635 (2006).

[5] L. Travis, J. Michael, J. Vac. Sci. Technol. A 31 061312 (2013).

[6] A.V. Andreev, I.Y. Litovchenko, A.D. Korotaev, D.P. Borisov, J. Phys. Conf. Series 652, 012057 (2015).

[7] I.A. Kurzina, E.V. Kozlov, Y.P. Sharkeev, Nanocrystalline Intermetallic and Nitride Structures Formed during Ion-Beam Exposure, NTL Publ., Tomsk 2008, (in Russian).

[8] D.L. Alontseva, S.N. Bratushka, M.V. Il'yashenko, M.V. Makhmudov, N.V. Prokhorenkova, Phys. Met. Metallogr. 113, 8 (2012).

[9] D. Alontseva, N. Prokhorenkova, Mater. Sci. Eng. 012026 87, (2015).

[10] D.L. Alontseva, A.L. Krasavin, A.V. Russakova, T.A. Kolesnikova, G.S. Bektasova, Mater. Sci. 22, 2 (2016).

[11] D. Alontseva, E. Ghassemieh, J. Phys. 644, 012009 (2015).

[12] A.L. Krasavin, M.D. Starostenkov, Fundamental'nye problemy sovremennogo materialovedenia (Basic Problems of Material Science) 13 (4), 548 (2016) (in Russian).

[13] D.L. Alontseva, A.L. Krasavin, T.A. Kolesnikova, A.V. Russakova, Acta Phys. Pol. A 125, 1275 (2014). 